Bangladesh Journal of Anatomy January 2014, Vol. 12, No. 1 pp. 11-13

\title{
Observational Study of Variations in Termination of the Common Bile Duct in Human Cadaver
}

\author{
Laila Farzana Khan ${ }^{1}$, Humaira Naushaba², Jubaida Gulshan Ara $^{3}$
}

\begin{abstract}
Context: The union of the distal portion of the common bile duct and the main pancreatic duct varies. They together may form short common channel or long common channel or may open separately into the second part of the duodenum. So detailed anatomical knowledge is essential for any surgical or endoscopic treatment of this region.
\end{abstract}

Materials and Methods: A cross sectional descriptive type of study was carried out in the department of Anatomy, Sir Salimullah Medical College on sixty two (62) human cadaveric extra hepatic biliary apparatus with pancreatic duct. The samples were collected from unclaimed dead bodies that were under examination in the department of Forensic Medicine of Dhaka Medical College, Dhaka and Sir Salimullah Medical College, Dhaka. The present study was conducted to observe the variations in termination of common bile duct with main pancreatic duct in human cadavers.

Results: The common bile duct was found to unite with main pancreatic duct within the duodenal wall in $61.3 \%$ cases and outside the duodenal wall in $38.7 \%$ cases.

Conclusion: The findings of the present study revealed that the termination of the common bile duct varies from individual to individual.

Keywords: Common bile duct, termination, variation.

\section{Introduction}

The anatomy in the distal portion of the common bile duct somewhat varies between individuals ${ }^{1}$. In about $70 \%$ of people, the common bile duct and main pancreatic duct unite outside the duodenal wall and then traverse the duodenal wall as a single duct, in about $20 \%$ of people, the ducts join within the duodenal wall and have a short or no common channel but opens through same opening into the duodenum and in about $10 \%$ of people they exit via separate openings into the duodenum ${ }^{2}$. Union of the pancreatic and common bile duct outside the ampulla of Vater is more frequent in Japan which predispose to both gallbladder carcinoma and choledochal cyst $^{3}$. Different diseases related to biliary pathway are diagnosed clinically and

1. Assistant Professor, Department of Anatomy, Dhaka National Medical College, Dhaka.

2. Professor and Head, Department of Anatomy, Sir Salimullah Medical College, Dhaka.

3. Assistant Professor, Department of Anatomy, Sir Salimullah Medical College, Dhaka.

Correspondence: Dr. Laila Farzana Khan confirmed by various non invasive as well as invasive procedures, such as ERCP (Endoscopic retrograde cholangio pancreatography), PTC (Percutaneous transhepatic cholangiography), choledochoscopy etc $^{4}$. The distal variation of termination of common bile duct should also serve as a danger signal in those cases where common bile duct is blocked by stone or tumor. In such cases the surgeon should proceed with caution so that a false passage or leakage of ducts will not be made ${ }^{5}$. Therefore, it is very important to have a thorough knowledge about the anatomy of variations of terminations of common bile duct in successful detection and proper treatment thereby decreasing morbidity and mortality rates during hepatobiliary surgery.

\section{Materials and Methods}

The present study was performed on sixty two (62) human cadaveric extra hepatic biliary apparatus with pancreatic ducts. The specimens were collected from unclaimed dead bodies that were under examination in the department of Forensic Medicine of Dhaka Medical College, Dhaka and Sir 
Salimullah Medical College (SSMC), Dhaka from July 2010 to June 2011 . The collected specimens were washed gently and thoroughly with running tap water and preserved in $10 \%$ formol saline solution for fixation and preservation. After fixation the formalin fixed samples were washed with running tap water and taken in a wax tray. The unwanted tissues from the specimens were removed carefully with the help of scissor and dissecting forceps. Then the union of the common bile duct with the main pancreatic duct was observed and its variations in termination were recorded (Fig 1a and Fig 1b).

\section{Ethical clearance}

This study was approved by the Ethical Review Committee of Sir Salimullah Medical College, Dhaka

\section{Results}

The common bile duct unites with the main pancreatic duct within the duodenal wall and forms the hepatopancreatic ampulla (of Vater). It was found in thirty eight (38) samples out of sixty two (62) and the percentage was $61.3 \%$. The common bile duct unites with the main pancreatic duct outside the duodenal wall and forms the hepatopancreatic ampulla. It was found in twenty four (24) samples out of sixty two (62) and the percentage was $38.7 \%$.

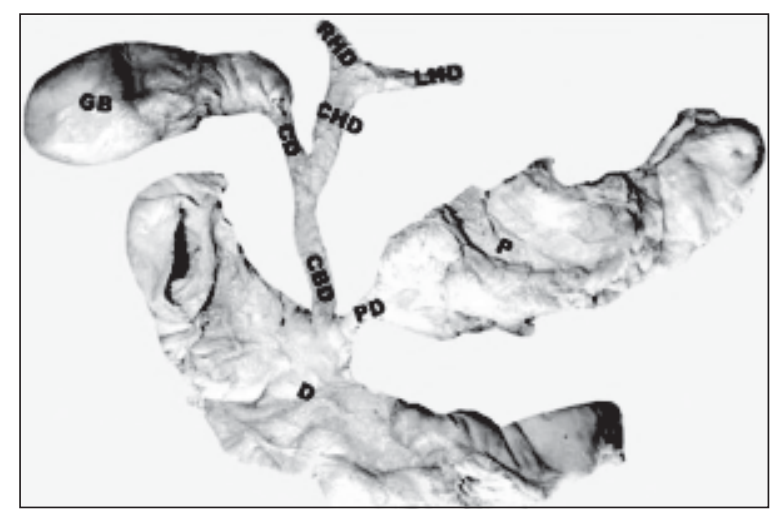

Fig.-1a: Photograph showing the union of common bile duct with main pancreatic duct within the duodenal wall. Gb-gallbladder, CD-cystic duct, CHD-common hepatic duct, RHD-right hepatic duct, LHD-left hepatic duct, CBD-common bile duct, $P D$ pancreatic duct, $P$-pancreas, $D$ - duodenum.

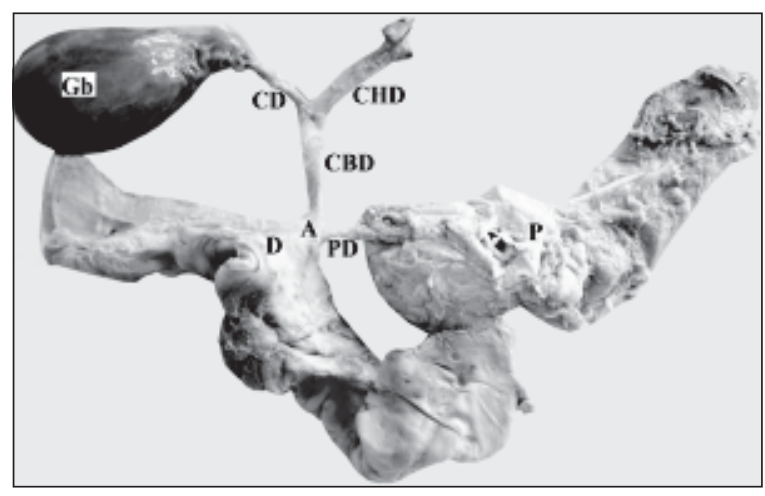

Fig 1b: Photograph showing the union of common bile duct with mainpancreatic duct outside the duodenal wall. Gb-gallbladder CD-cystic duct CHDcommon hepatic duct, CBD-common bile duct, $P D$ pancreatic duct, A-ampulla, P-pancreas, Dduodenum.

\section{Discussion}

In the present study, the common bile duct was found to unites with the main pancreatic duct forming the hepatopancreatic ampulla within the duodenal wall was found in 38 samples (61.3\%). Union of main pancreatic duct with the common bile duct outside the duodenal wall was found in 24 samples (38.7\%). The observation of the present study agreed with the statement of Standring $(2008)^{6}$, Moore \& Dalley $(2006)^{7}$ and Gore \& Levine in $1994^{8}$. Brunicardi (2010) ${ }^{9}$ observed that in about $70 \%$ of people, two ducts unite outside the duodenal wall and in $20 \%$ of people the two ducts join within the duodenal wall. In Japan, Silverberg $(2006)^{10}$ reported that the union of the distal common bile duct and main pancreatic duct frequently occur outside the hepatopancreatic ampulla (of Vater). Keddie et al ${ }^{11}$ found $23 \%$ anomalies in the termination of common bile duct among 120 samples.

\section{Conclusion}

From the findings of this study, it can be concluded that the mode of termination of common bile duct with main pancreatic ducts vary. The observation and result of present study are expected to standardize the anatomical study of common bile duct termination in Bangladeshi people. Further 
studies using larger samples covering both sexes and different study population are recommended. Besides postmortem study, using more advanced methods such as cholecystography, CT scan, MRI, ERCP and endoscopic ultrasound guided evaluations are also suggested.

\section{References}

1. Gore RM, Levine MS, Laufer I. (Textbook of gastrointestinal radiology vol 2). $5^{\text {th }}$ ed. Philadelphia: W B Saunders 1994: 1570-71.

2. Brunicardi FC. Schwartz's principles of surgery. $9^{\text {th }}$ ed. New York: Mc Graw Hill 2010: 1136-42.

3. Silverberg SG. Silverberg's principles and practice of surgical pathology and cytopathology. $4^{\text {th }}$ ed. Philadelphia: Churchill Livingstone 2006: 1576.

4. Williams NS, Bulstrode CJK, O'connel PR. Bailey \& Love's short practice of surgery. $25^{\text {th }}$ ed. London: Hodder Arnold 2008: 1111.

5. Paul S, Jacinth JS, Muniappan V: Variations of the extra hepatic biliary tract: Cadaveric study; IOSR Journal of Dental and Medical Sciences, Tamilnadu, India 2013; 10(1): 46-50.

6. Standring S. Gray's anatomy the anatomical basis of clinical practice. $40^{\text {th }}$ ed. London: Churchill Livingstone 2008: 1177-81.

7. Moore KL, Dalley II AF. Clinically oriented anatomy. $5^{\text {th }}$ ed. Philadelphia: Lippincott Williams \& Wilkins 2006: 301-04.

8. Gore RM, Levine MS, Laufer I. (Textbook of gastrointestinal radiology vol 2). $5^{\text {th }}$ ed. Philadelphia: W B Saunders 1994: 1571.

9. Brunicardi FC. Schwartz's principles of surgery. $9^{\text {th }}$ ed. New York: Mc Graw Hill 2010: 1138.

10. Silverberg SG. Silverberg's principles and practice of surgical pathology and cytopathology. $4^{\text {th }}$ ed. Philadelphia: Churchill Livingstone 2006: 1578.

11. Keddie et al: Anomalous terminations of the common bile duct in duodenum; Royal Infirmary, Manchester, Eng 1974; 184(5): 626-32. 